\title{
Effect of Stevia on the Chemical Composition of Low Calorie Herbal Kulfi
}

\author{
Durga Singh, Dinesh Chandra Rai, Basant Kumar Bhinchhar* and \\ Bajarang Lal Choudhary
}

\author{
Department of Animal Husbandry and Dairying, Institute of Agricultural Sciences, \\ BHU, Varanasi, India \\ *Corresponding author
}

\begin{tabular}{|c|c|}
\hline & A B S T R A C T \\
\hline Keywords & \multirow{4}{*}{$\begin{array}{l}\text { Stevia (Rebaudiana bertoni) is a natural herb, it's have many medicinal } \\
\text { properties like Stevia prevents diabetes, decreases weight, prevents tooth } \\
\text { decay, and increases digestion. Kulfi is a famous frozen dairy dessert from } \\
\text { the Indian Subcontinent. For the process optimization of herbal Kulfi by } \\
\text { response surface methodology, the experiments were conducted according } \\
\text { to Central Composite Rotatable Design (CCRD) with three variables at two } \\
\text { actual levels. Response surface methodology was effective in optimizing } \\
\text { process parameters for the herbal Kulfi comprising Herbal mixes in range } \\
\text { (2-4), Stevia is in range (50-70), and sugar is in range (30-50). The } \\
\text { optimum processing conditions were experimentally verified and proven to } \\
\text { be adequately reproducible. }\end{array}$} \\
\hline $\begin{array}{l}\text { Optimization, Ash, } \\
\text { Herbal kulfi, Fat, } \\
\text { Carbohydrate, } \\
\text { Central composite } \\
\text { rotatable design. }\end{array}$ & \\
\hline Article Info & \\
\hline $\begin{array}{l}\text { Accepted: } \\
\text { 17 June } 2017 \\
\text { Available Online: } \\
10 \text { August } 2017\end{array}$ & \\
\hline
\end{tabular}

\section{Introduction}

Recent technological developments in processing of food for value addition, guided by the change of consumer preferences led to the development of new products. [1] And [2] Stevia (Stevia rebaudiana Bertoni) is a natural herb native of northeastern Paraguay. Various studies on functional properties of Stevia were revealed the suitability of substituting in different products. Varieties of Stevia substituted products formulated and developed had different levels of acceptability. Besides its sweetness properties, Stevia prevents diabetes, decreases weight, prevents tooth decay, and increases digestion [3] and [4]. Kulfi is a famous frozen dairy dessert from the Indian Subcontinent. It was often described as traditional Indian Subcontinent ice cream. Thus it can be concluded that the plant based Stevia herb is a low calorie nutritious component has an immense potential in the main stream of food processing industries as a health and dietetic benefactor.The pleasant sweet taste, low cost and high energy value make it the most desirable food sweetener.

\section{Materials and Methods}

\section{Preparation of herbal extract}

Fresh herbs viz. Fennel (Foeniculum vulgare), Tulsi (Ocimum sanctum L.) Pan Patta (Piper 
betle) was collected from local market of Varanasi. Hundred grams of each shade dried herbs material was extracted in distilled water for 6 hours at slow heat. Every 2 hr. it was filtered through 8 layers of muslin cloth and centrifuged at $5000 \mathrm{~g}$ for $15 \mathrm{~min}$. The supernatant was collected. This procedure was repeated twice and after $6 \mathrm{hr}$. supernatant was concentrated to make the final volume one-fifth of the original volume. The extract was autoclaved at $121^{\circ} \mathrm{C}$ and $15 \mathrm{lbs}$ pressure, and stored at $4^{\circ} \mathrm{C}$.

\section{Preparation of brine mixture}

Brine mixture was a mixture of ice and salt. For preparation of brine mixture ice and salt mix with a fix ratio (6:1). Firstly crush the ice in small parts and put in earthenware pot (matka) then after salt was add in fix quantity.

\section{Preparation of herbal Kulfi}

Herbal Kulfi was prepared from milk. Freshly drawn raw milk was received and straining to remove visible dust and dirt particles through muslin cloth. After straining 2 litre of milk was taken in shallow open pan and it was heated to simmering temperature $90-95^{\circ} \mathrm{C}$ to reduce the volume to half of whole milk.

Thereafter, the concentrated milk was cooled at $60-65{ }^{\circ} \mathrm{C}$ temperature then after the stabilizer sodium alginate @ $0.15 \%$ was mixed with tissue homogenizer then again milk was cooled at $25-30^{\circ} \mathrm{C}$ temperature. The sweetener (sugar +Stevia) as mixed @13\% and herbal extract was added in different percentage like 2.0, 3.0 and $4.0 \%$. Mixture was filled in plastic cones and sealed with cone caps.

After sealing the cones were immersed in brine mixture in an earthenware pot (Matka). Vigorous agitation was applied from time to time to affect heat transfer and expedite the freezing process. Cones were kept in brine mixture for 4-5 hours. After sufficient hardness the cone was collected and Kulfi was removed from cone with the help of knife. Herbal Kulfi were finally stored at $5 \pm 1{ }^{\circ} \mathrm{C}$ (Fig. 1).

\section{Estimation of yield of herbal Kulfi}

The yield of herbal Kulfi was calculated using following formula:

Yield of herbal Kulfi $=\frac{\text { Weight of herbal Kulfi(kg.) } \times 100}{\text { Weight of Mix }}$

\section{Statistical analysis and optimization}

The statistical analysis was done by CCRD (Central Composite Rotatable Design) method using a commercial statistical software package design expert 8.0.5 for the optimization of Low Calorie Herbal Kulfi. Analysis of variance (ANOVA) was performed on experimental data for fitting the model represented by equation to examine the statistical significance of model terms.

$Y k=f(A, B, C)$

Where,

A is Herbal mix (\%), B is Stevia (\%) and C is sugar $(\%)$. The responses were represented as $\mathrm{Y}_{1}$ (Color and appearance), $\mathrm{Y}_{2}$ (flavor), $\mathrm{Y}_{3}$ (Body and texture), Y4 (sweetness), Y5 (Consistency) and Y6 (Over all acceptability). The general assumption for optimization is Yk where, $\mathrm{K}$ is $(1,2,3,4,5,6)$ is function of independent parameters shown by the above equation.

The most common used model for denoting response as a function of independent parameter is a second order polynomial equation of the form described below.

$\mathrm{Yk}=\beta \mathrm{o}+\sum \beta \mathrm{i} \mathrm{Xi}+\sum \beta \mathrm{ii}+\mathrm{X}^{2}+\sum \beta \mathrm{ijXiXj}$ 
Where, $Y k$ is the response, $\beta \mathrm{o}, \beta \mathrm{i}, \beta \mathrm{ii}$ and $\beta \mathrm{ij}$ are constant, linear, quadratic and cross product regression coefficient, respectively and Xi's are the actual value of the independent variables. The above equation was used to appropriate the function fk using the response surface method (RSM).

\section{Effect on chemical composition of herbal Kulfi}

Effect of replacement of sugar with Stevia on the chemical composition of herbal Kulfi, was summarized and is presented in the form of table 1 . The effects of different treatments on the chemical composition of herbal Kulfi are given in the Appendices.

\section{Fat content}

The fat of control herbal Kulfi was recorded 10 as against 10.8, 10.9 and 11.2 for 50,60 and $70 \%$ sugar reduction through $0.05,0.06$ and $0.07 \%$ Stevia addition, respectively. The fat of control sample was significantly lower than that of all treated Kulfi samples. Figure 2 shows that the level of Stevia increased from 0.05 to $0.06 \%$, increased the fat significantly.
However, as the level of Stevia increased from 0.06 to $0.07 \%$ no significant effect on fat was noticed.

\section{Protein content}

The protein of control herbal Kulfi was recorded 6.3 as against 6.7, 7.1 and 7.2 for 50 , 60 and $70 \%$ sugar reduction through 0.05 , 0.06 and $0.07 \%$ Stevia addition, respectively. The protein of control sample was significantly lower than that of all treated Kulfi samples.

Figure 3 shows that the level of Stevia increased from 0.05 to $0.06 \%$ increased the Protein significantly. However, as the level of Stevia increased from 0.06 to $0.07 \%$ no significant effect on Protein was noticed.

\section{Carbohydrate content}

The carbohydrate of control Kulfi was recorded 22.6 as against $16.8,15.7$ and 13.8 for 50,60 and $70 \%$ sugar reduction through $0.05, \quad 0.06$ and $0.07 \%$ Stevia addition, respectively. The carbohydrate of control sample was significantly higher than that of all treated Kulfi samples.

Proportion of various ingredients and treatments

\begin{tabular}{ccccc}
\hline & \multicolumn{4}{c}{ Treatment } \\
\cline { 3 - 5 } Ingredient & $\mathbf{T}_{\mathbf{0}}$ & $\mathbf{T}_{\mathbf{1}}$ & $\mathbf{T}_{\mathbf{2}}$ & $\mathbf{T}_{\mathbf{3}}$ \\
\cline { 1 - 4 } Sugar & $100 \%$ & $50 \%$ & $40 \%$ & $30 \%$ \\
\cline { 1 - 4 } Stevia & $0 \%$ & $0.05 \%$ & $0.06 \%$ & $0.07 \%$ \\
\cline { 1 - 3 } Herbal mix & $0 \%$ & $2 \%$ & $3 \%$ & $4 \%$ \\
\hline
\end{tabular}

Table.1 Composition of different levels of sugar reduced and different levels of Stevia added Kulfi

\begin{tabular}{|c|c|c|c|c|c|c|c|}
\hline \multirow{2}{*}{$\begin{array}{l}\text { Levels of } \\
\text { sugar } \\
\text { reduction } \\
(\%)\end{array}$} & \multirow{2}{*}{$\begin{array}{l}\text { Levels of } \\
\text { Stevia } \\
\text { addition (\%) }\end{array}$} & \multicolumn{6}{|c|}{ Constituents (\%) } \\
\hline & & Fat & Protein & Carbohydrate & Ash & Moisture & $\begin{array}{l}\text { Melting } \\
\text { rate(mg) }\end{array}$ \\
\hline 100 & 0 & 10 & 6.3 & 22.6 & 0.98 & 60 & 18.2 \\
\hline 50 & 0.05 & 10.8 & 6.7 & 16.8 & 1.08 & 63.9 & 14.9 \\
\hline 60 & 0.06 & 10.9 & 7.1 & 15.7 & 1.09 & 65.8 & 12.3 \\
\hline 70 & 0.07 & 11.2 & 7.2 & 13.8 & 1.10 & 66.9 & 12.1 \\
\hline
\end{tabular}


Fig.1 Flow chart for preparation of herbal Kulfi

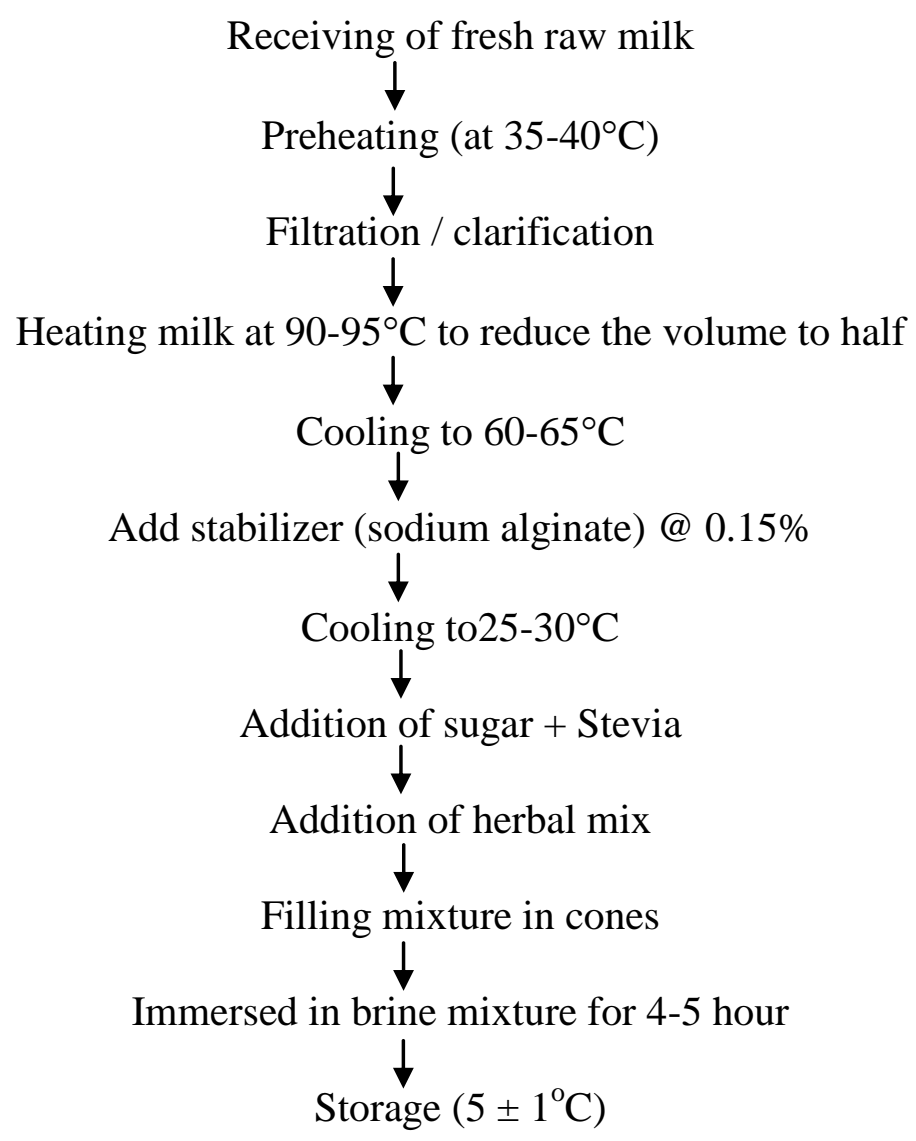

Fig.2 Effect on fat

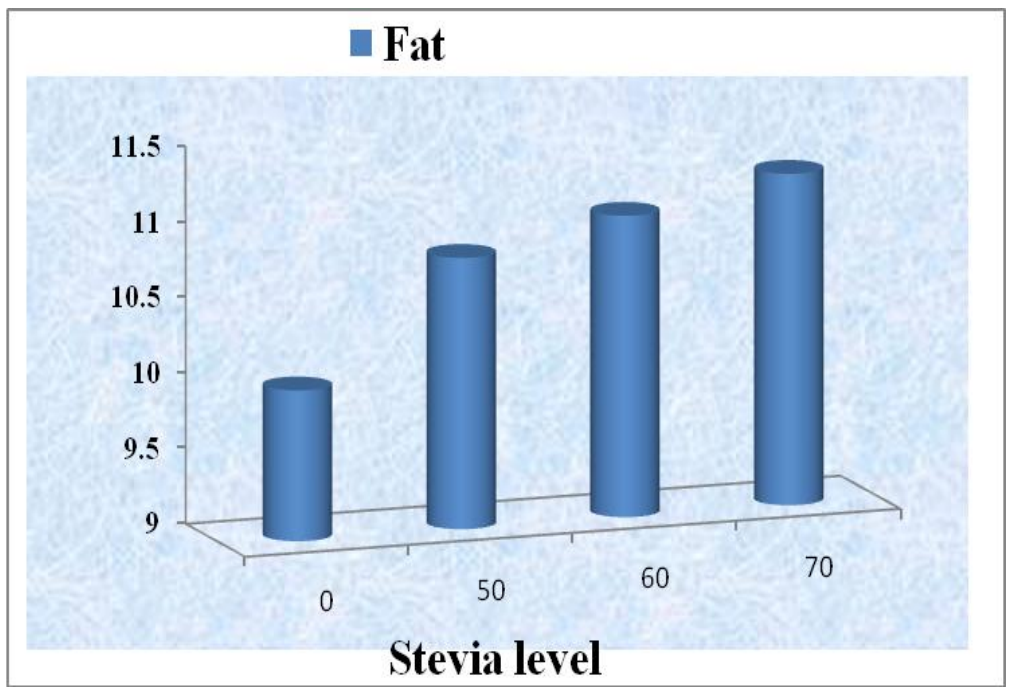


Fig.3 Effect on protein

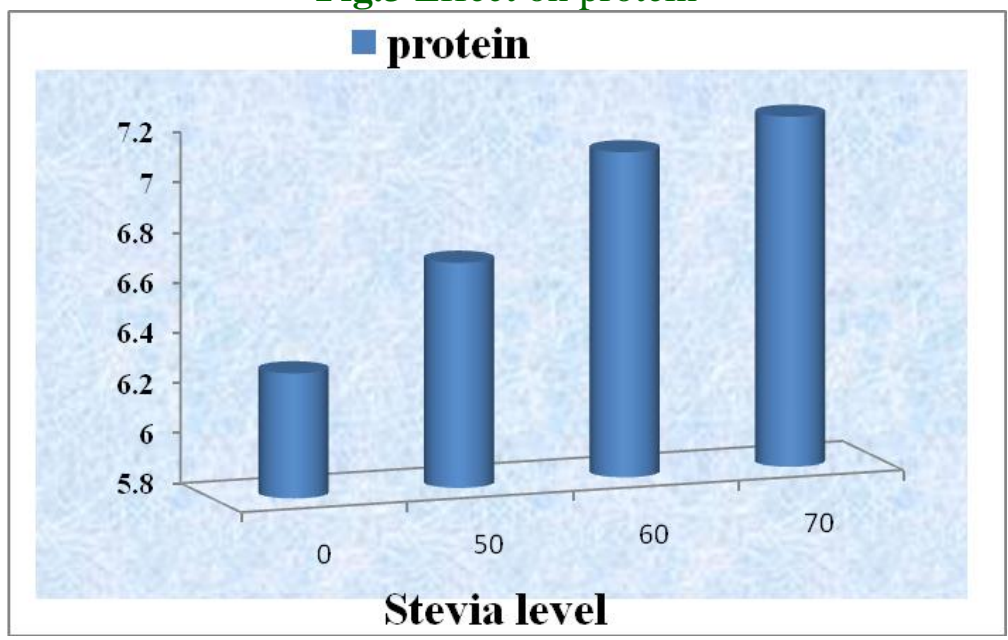

Fig.4 Effect on carbohydrate

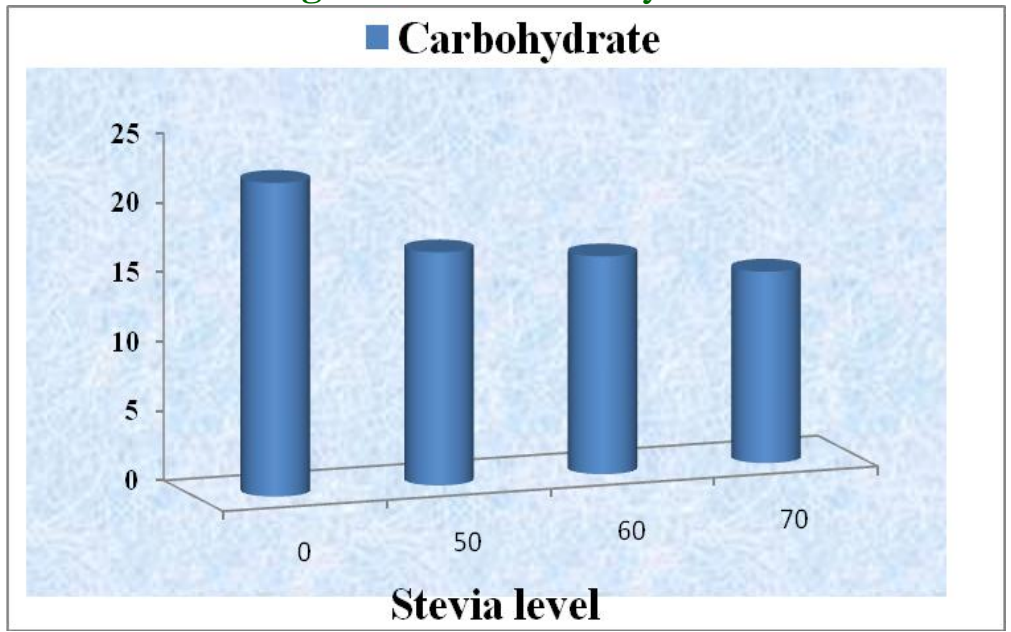

Fig.5 Effect on Ash

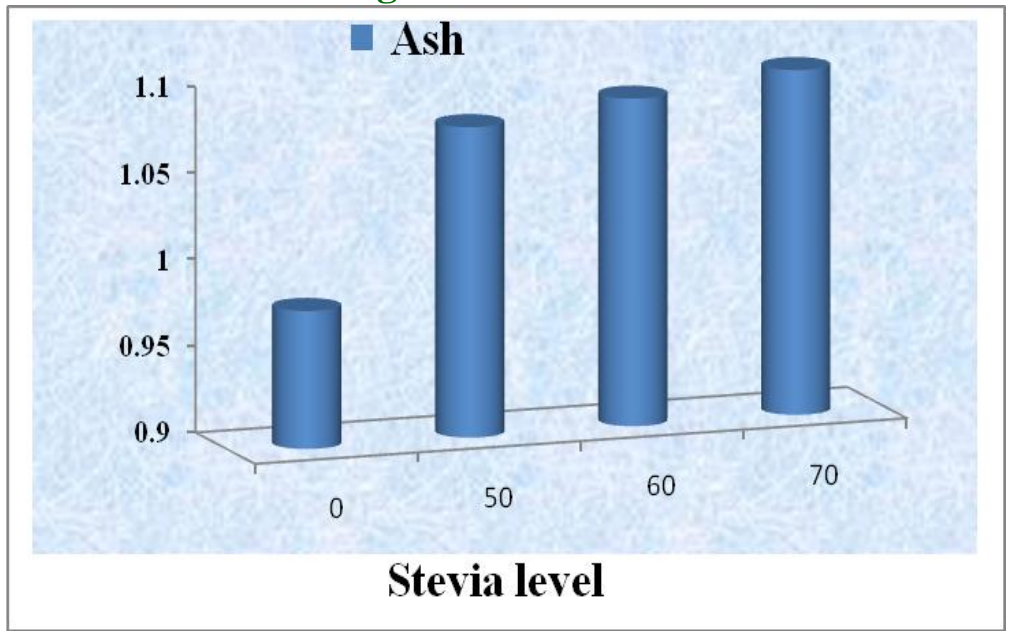


Fig.6 Effect on moisture

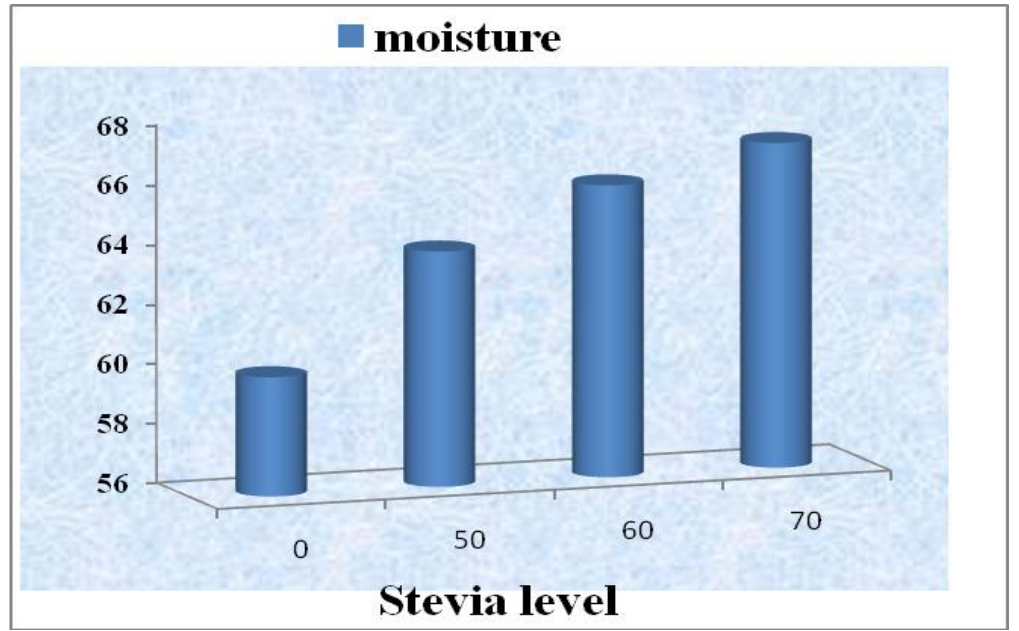

Fig.7 Effect on melting rate

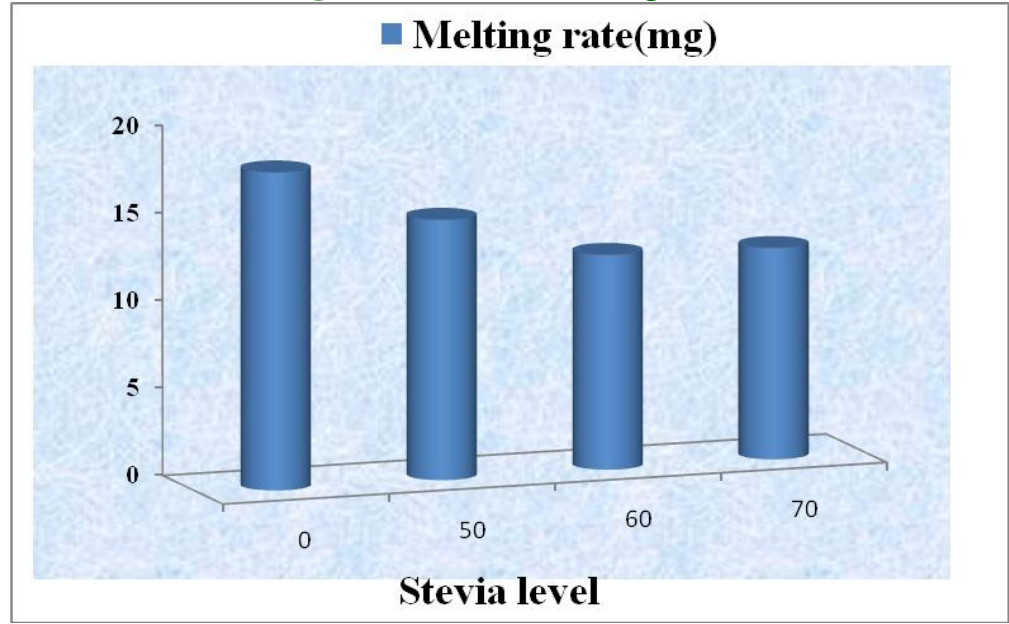

Figure 4 shows that the level of Stevia increased from 0.05 to $0.06 \%$ decreased the carbohydrate significantly. However, as the level of Stevia increased from 0.06 to $0.07 \%$ no significant effect on Ecarbohydrate was noticed.

This is due to decreased level of sugar which was a major contributor to carbohydrate level in Kulfi. Among three treated Kulfi samples, as the percentage of sugar reduction increased, the Ecarbohydrate level of Kulfi decreased. This is again due to increased replacement of sugar with non-caloric stevia. [5] Found that replacing sucrose with stevia reduced the carbohydrate value of the frozen yoghurt by about $33.86 \%$ when $75 \%$ sucrose was replaced with Stevia.

\section{Ash content}

The ash of control herbal Kulfi was recorded 0.98 as against $1.08,1.09$ and 1.1 for 50,60 and $70 \%$ sugar reduction through $0.05,0.06$ and $0.07 \%$ Stevia addition respectively. The ash of control sample was significantly lower than that of all treated Kulfi samples.

Figure 5 shows that the level of Stevia increased from 0.05 to $0.06 \%$ increased the ash content significantly. However, as the level of Stevia increased from 0.06 to $0.07 \%$ no significant effect on ash content was noticed. 


\section{Moisture content}

The moisture of control herbal Kulfi recorded was 60 as against 63.9, 65.8 and 66.9 for 50, 60 and $70 \%$ sugar reduction through $0.05,0.06$ and $0.07 \%$ Stevia addition, respectively. The moisture of control sample was significantly lower than that of all treated Kulfi samples. Figure 6 shows that the level of Stevia increased from 0.05 to $0.06 \%$ increased the moisture significantly. However, as the level of Stevia increased from 0.06 to $0.07 \%$ no significant effect on moisture was noticed.

\section{Melting rate}

The melting rate $(\mathrm{mL} / 15 \mathrm{~min})$ of control Kulfi recorded was 18.2 as against 14.9, 12.3 and 12.1 for 50,60 and $70 \%$ sugar reduction through 0.05, 0.06 and $0.07 \%$ Stevia addition, respectively. The melting rate of control sample was significantly higher than that of all treated Kulfi samples.

Figure 6, as the level of Stevia increased from 0.05 to $0.06 \%$ decreased the melting rate significantly. However, as the level of Stevia increased from 0.06 to $0.07 \%$ no significant effect on melting rate was noticed. The melting rate decreased due to reduction in sugar level and increase moisture content of Kulfi. So at higher levels of sugar replacement increase in free moisture content and subsequent increase in large ice crystal formation might be the reason for decreased melting rate in the Kulfi samples. [6] Also reported that in ice cream mix, whenever levels of sugar replacement (20, 40 and $60 \%$ ) increased by Stevia addition, there was reduction in the melting rate.

In conclusion, twenty different runs according to the CCRD were used to study the physicochemical parameters of herbal Kulfi. Response surface methodology was effective in optimizing process and physicochemical parameters. The regression equations obtained in this study can be used for optimum conditions for desired responses within the range of conditions applied in this study. Graphical techniques, in connection with response surface methodology (RSM), aided in locating optimum operating conditions, which experimentally verified and proven to be adequately reproducible. Optimum solution by numerical optimization obtained was Herbal mix, Stevia and sugar 3.69,50 and 50 to get maximum possible quality, solute gain and sensory score.

\section{References}

1. Savita, S. M., Sheela, K., Sunanda, Sharan, Shankar, A. G. and Ramakrishna, Parama. (2004). Stevia rebaudiana - A functional component for food industry. J. Hum. Ecol, 15(4): 261-264.

2. Maurya, S. C. and Singh, D. P. (2007). Studies on standardization for preparation of quailtyKulfi. Indian Dairyman, 59(9): 56-59.

3. Rao, H. G. R. and Giri, A. (2009). Stevia natural sweetener for dairy products. Indian Dairyman, 61(11): 68-73.

4. Murthy, M. R., Sharanagouda, B., Jayaprakash, H. M. and Ramanjaneyalu, G. (2009). Studies on the preparation of filled Kulfi. Mysore Journal of Agricultural Sciences, 43(3): 597-599.

5. Salem, A. S. and Massoud, M. I. (2003). Effect of using Stevia rebaudiana (Bertoni) leaves powder as natural non caloric sweetener on the physico-chemical properties of fibre fortified frozen yoghurt. Egypt J. Dairy Sci, 311 (61): 70.

6. Salama F. M. M. (2004). The use of some natural sweeteners in ice cream manufacture. Egypt J Dairy Sci, 322:355366.

\section{How to cite this article:}

Durga Singh, Dinesh Chandra Rai, Basant Kumar Bhinchhar and Bajarang Lal Choudhary. 2017. Effect of Stevia on the Chemical Composition of Low Calorie Herbal Kulfi. Int.J.Curr.Microbiol.App.Sci. 6(8): 1190-1196. doi: https://doi.org/10.20546/ijcmas.2017.608.147 